\title{
Origin of the septum in the canid auditory bulla: Evidence from morphogenesis
}

\author{
Dmitry V. IVANOFF
}

Ivanoff D. V. 2000. Origin of the septum in the canid auditory bulla: Evidence from morphogenesis. Acta Theriologica 45: 253-270.

Morphogenesis of the intrabullar septum in Canis lupus Linnaeus, 1758 and Vulpes vulpes (Linnaeus, 1758), as well as the definitive septal morphology within the family, demonstrate that no bone of the auditory bulla bends its edge inwards the bulla to produce a septum. Instead, the canid intrabullar partition is a result of the development of the ventral entotympanic sinus, an additional cavity within the hypotympanic space. This sinus appears as a separate inflation of the ventral part of the caudal entotympanic and expands beneath the surrounding wall of the bulla. In this way the boundary of the sinus-forming inflation enters partially into the bulla cavity and becomes a partition consisting of two compositionally different components: the dorsal and ventral septa. The dorsal septum is exclusively caudal-entotympanic; the ventral septum is apparently bilaminar since it is formed by the growth of the caudal entotympanic over the ectotympanic. The only argument against the homology of canid and felid septa is a difference in their caudal-entotympanic regions participating in the septum-forming inflation. Currently available information about the canid septal patterns strongly suggests that it is the presence of the ventral entotympanic sinus that can be used as an auditory-bulla character uniquely shared by Canidae.

Palaeontological Museum, National Museum of Natural History, 15 Bogdan Khmelnitsky St., Kiev, UA-01601, Ukraine, e-mail: pal-museum@profit.net.ua

Key words: Carnivora, Canidae, auditory bulla, ontogeny, phylogeny

\section{Introduction}

Structure of the auditory region of the skull and, particularly, the auditory bulla, bears an extreme significance for the reconstruction of carnivoran phylogeny. In the course of the bulla morphogenesis, its bones (ectotympanic, rostral and caudal entotympanics) undergo diverse transformations determining the definitive bulla architecture. This structure, being complemented by the morphology of the petrosal and other adjacent cranial elements, exhibits the patterns which are relatively stable among the higher-level taxa of Carnivora and, therefore, so important for systematics.

Early students of the carnivoran auditory region (Turner 1848, Flower 1869) paid special attention to the septum bullae, a bone partition dividing the bulla into two chambers. Flower (1869), classifying the major taxa of recent Carnivora, noted its presence in the Felidae, Viverridae, Cryptoproctidae, Protelidae (families belonging to the group Aeluroidea erected by that author) and the Canidae (group 
Cynoidea). In the remaining group, Arctoidea, the 'distinct and definite' septum was said to be lacking. Flower believed the distinction of the canid septum from that of aeluroids is only in its relative size. He treated canids as a group 'intermediate' between aeluroids and arctoids, occupying a 'central' position within the Carnivora. Subsequent attempts of evolutionary considerations made it even more clear that the Canidae are morphologically primitive carnivorans whose relationships with more advanced groupings of the order are vague.

Careful ontogenetic data were needed to test Flower's (1869) assumption of homology of the carnivoran intrabullar septa. Wińcza $(1896,1898)$ suggested that the felid septum bullae is formed by the upward growth of the contacting edges of ectotympanic and entotympanic. In this way they become bent inwards the bulla cavity and jointly produce a bilaminar partition. No objection has ever been raised to Wińcza's model. As to the partial septum in the canid auditory bulla, the various and discrepant suggestions on its origin were made (Winge 1895, Van Kampen 1905, Holz 1931, Hough 1953, Hunt 1974, 1987, Wang and Tedford 1994). Despite common agreement about the crucial importance of this problem, it remains an extremely controversial issue.

When the interest in the basicranial morphology was rekindled from the phylogenetic systematics standpoint, Tedford (1976: 366) proposed, as a character uniquely shared by canids, 'a low septum formed from the inbent edge of the entotympanic'. The opinion has gained general favour. Up to the present, the solely caudal-entotympanic nature of the canid septum is considered virtually as the only synapomorphy for the Canidae (eg Flynn et al. 1988, Wang and Tedford 1994, Tedford et al. 1995, Munthe 1997). However, neither the exclusive contribution of caudal entotympanic nor the inflection of the bone edge (as a septum-forming process) has ever been sufficiently demonstrated.

The present study is an attempt to clarify what bone elements, and in which manner, compose the canid intrabullar septum. It is based on the examination of the auditory bulla morphogenesis in the gray wolf Canis lupus Linnaeus, 1758 and red fox Vulpes vulpes (Linnaeus, 1758) and on the analysis of morphological diversity of the septum in adults of recent canid species (subfamily Caninae sensu Tedford et al. 1995). Particular emphasis was placed on the inspection of the youngest specimens whose intrabullar septa had never been described in detail.

\section{Material and methods}

A total of 68 skulls of 17 canine species were examined (see Appendix 1 for the list of specimens). The collections used are housed in the following institutions: Institute of Systematics and Evolution of Animals, Cracow (ISEA); Palaeontological Museum, National Museum of Natural History, Kiev (NMNH-P); Zoological Museum, National Museum of Natural History, Kiev (NMNH-Z); Sherchenko National University Zoological Museum, Kiev (ZMKU); Lomonosov University Zoological Museum, Moscow (ZMMU).

The material on the development of intrabullar partition was represented by the skulls of $C$. lupus and, somewhat more poorly, V. vulpes. Both cranial series included the skulls showing the earliest stages of septum morphogenesis. It is precisely these previously unknown septal patterns that offer 
new insight into the problem. The exact age of individuals, though desirable, was not critical, however, for the purpose in hand. Approximate age of juveniles was determined using data of Gursky (1973) for the wolf, and Linhart (1968) and Yudin (1986) for the fox. Such estimations cannot be precise while those few works on which an age determination might be based are contradictory (eg Yudin 1989 vs Gursky 1973, or Yudin 1986 vs Markina 1962).

The specimens with damaged auditory region were used, and the intact ones in which the floor of the bulla was partly removed to an extent that the internal surface of the bulla was visible. For simplicity the line drawings do not include any cranial components other than ectotympanic and entotympanics. The terms 'anteroventral septum', 'posteroventral septum', 'ventral entotympanic sinus' and 'preseptal crest' are introduced in Results. The abbreviations for anatomical terms are listed in Appendix 2.

\section{Basic earlier hypotheses on the origin of canid septum}

For a better understanding of the problem, the previous viewpoints on the nature of the canid intrabullar partition are briefly mentioned below. In 1895, Winge (cited by Van Kampen 1905) suggested that the canid septum ossifies in the fold of the mucous membrane. Van Kampen (1905) stated that the septum in canids is a resultant from the non-uniform resorption of the internal surface of the inflating bulla. In addition, he denied the autonomous ossification of the entotympanic portion of canid bulla (Fig. 1). Holz (1931) believed that the canid septum is composed of the osteophytes sitting on the internal surface of the bulla and coalescing with each other. Hough (1953) claimed that the intrabullar partition of the Canidae differs from that of Felidae only in the absence of ectotympanic

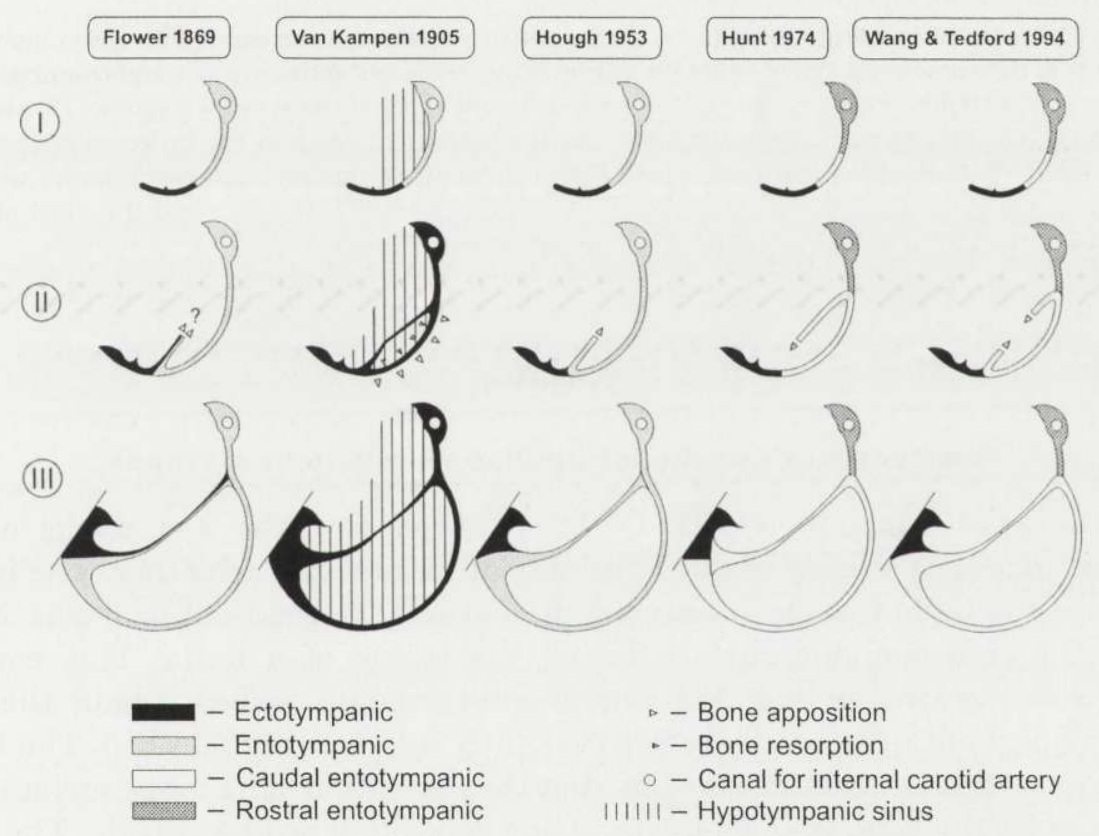

Fig. 1. Diagrams to illustrate the previous hypotheses about the canid intrabullar septum composition and development. Each column represents the bulla transverse section cut at the level of the septum anterior end (see Fig. 5, C for the location of section), at successive ontogenetic stages (I to III). Top is dorsal and right is medial. Only the ventral part of the ectotympanic, adjacent to the caudal entotympanic is shown. Note that (1) Van Kampen's model implies no septum-forming growth of bone edges inwards the bulla cavity, (2) the rostral entotympanic should make up a significant part of the bulla medial wall if the growth of the dorsal edge of caudal entotympanic is assumed. 
component. According to her (ibid., p. 110), the canid septum is 'formed entirely by the inbent margin of the entotympanic' (Fig. 1). Hunt (1974) also believed that the septum in canids develops from the caudal entotympanic alone. He emphasized, however, that it is formed through the inflection not of that edge of the caudal entotympanic that is in contact with the ectotympanic, but of the opposite (dorsomedial) one which is adjacent to the rostral entotympanic (Fig. 1).

The concept of the canid septum that is formed exclusively of the caudal entotympanic received wide acceptance (eg Tedford 1976, Flynn and Galiano 1982, Flynn et al. 1988, Wozencraft 1989, Wyss and Flynn 1993, Wang and Tedford 1994, Tedford et al. 1995, Munthe 1997). As regards the process of septum formation, the controversy has been limited mainly to the question: Which edge of the caudal entotympanic is inflected to create a septum?

The morphology of the earliest canids is not consistent with Hunt's (1974) model. Mitchell and Tedford (1973) reported that the septum in the North American Tertiary genus Hesperocyon Scott, 1890 is situated at the suture between the ectotympanic and caudal entotympanic. This character was extended by Tedford (1976) and Wang and Tedford (1996) to the whole family. According to Wang and Tedford (1994), a 'dorsal septum' (which is formed by the inflected dorsomedial edge of the caudal entotympanic) is lacking in Hesperocyon. Instead, a 'ventral septum' (located at the posterior region of the ectotympanic/caudal-entotympanic suture) is present. They believed that the dorsal septum begins to arise in more advanced hesperocyonines only. In Paraenhydrocyon josephi (Cope, 1881), both the dorsal and ventral septa are developed combining into a ring-like structure inside the bulla. In some derived hesperocyonines, the septum is confined to the anterior end of the bulla as it is in recent Caninae and some Borophaginae. The latter morphotype is assumed by Wang and Tedford (1994: 20) to be 'a derived condition from a more ubiquitous presence of the septum along all edges of the caudal entotympanic in early canids' (Fig. 1).

Hunt (1987) has recently pointed out that the ectotympanic also can enter into the composition of canid septum. His opinion on the formation of this structure is not quite explicit and comprises (1) the inflection of the caudal-entotympanic dorsal edge adjacent to the rostral entotympanic, (2) the partial protrusion of the medial rim of ectotympanic into the bulla cavity to join the inflected edge of caudal entotympanic, (3) the subsequent expansion of the caudal-entotympanic 'anterior pocket', which may add a lamina to the intrabullar ectotympanic. Finally, Hunt (1987) has stressed the need of further detailed examination of the ontogenetic development of canid bulla.

\section{Results}

\section{Morphogenesis of the intrabullar septum in Canis lupus}

In the gray wolf cub NMNH-P 1091, estimated to be 3-4 weeks old, the entotympanics are already ossified but not yet fused with each other. The internal surface of the bulla reveals an interesting feature, the clear-cut oval concavity on the caudal-entotympanic surface facing the inside of a bulla. This concavity occupies the ventral part of the caudal-entotympanic posterior half; the corresponding part of the external surface is slightly inflated (Fig. 2, VES). The bone in this region is extremely thin, showing that the resorption of its inner surface at this stage is not quite compensated by new bone deposition on the outside. The lateral margin of this fossa is adjacent to the suture between the ectotympanic and caudal entotympanic. Its medial margin is represented by the well-pronounced ridge which runs parallel to and substantially below the dorsal edge of the caudal entotympanic contacting the petrosal.

The dissection of the auditory bulla in the wolf cub NMNH-P 3720, aged 8 to 9 weeks, allowed examining the septum at the early stage of its formation. In this 

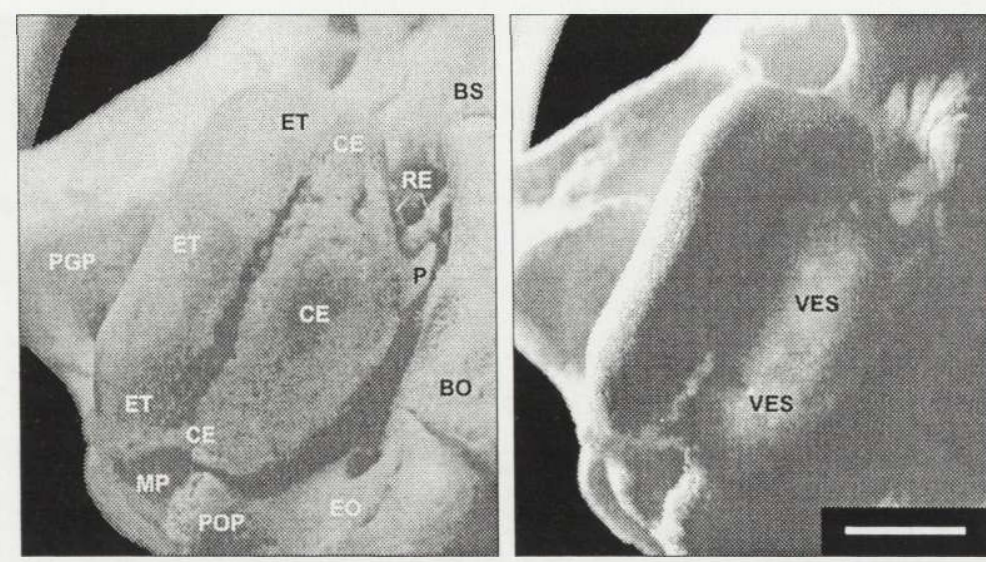

Fig. 2. Right auditory bulla of the juvenile Canis lupus, NMNH-P 1091, aged approximately 3 to 4 weeks (postero-ventro-medial view). On the right photograph, to show the position of the ventral entotympanic sinus at the incipient stage of its development the bulla is transilluminated. Most of the extrabullar portion of the rostral entotympanic is lost. Scale bar $5 \mathrm{~mm}$. See Appendix 2 for abbreviations.

specimen, the dorsal edge of the caudal entotympanic exhibits no tendency towards an inflection, both in the region of contact with the rostral entotympanic and posteriorly. Instead, the progressive enlargement of the above-mentioned local inflation is observed being most pronounced in the ventrolateral, anterior and dorsomedial directions (Figs 3 and 5II).

The ectotympanic/caudal-entotympanic suture contiguous to the inflation shows the following important transformation: two crests occur here, the larger one at the anterior part of the suture, and another sitting posteriorly (Figs 4 and 5II). Judging from the texture of bone surfaces and the position of these cristae, it can be convincingly suggested that both crests are formed through the growth of the caudal entotympanic over the tympanic ring to create a surface-to-surface contact (Figs 3 and 4). The edge-to-edge contact persists only in the space between the crests (Fig. 4).

Interestingly, at this developmental stage, the part of the medial rim of ectotympanic, anterior to the aforementioned inflation, is also inside the bulla. This is due to the caudal-entotympanic anterior portion which undergoes its own slight inflation and grows over the anterior part of the ectotympanic rim. As a result, an additional intrabullar crest appears, hereafter referred to as the preseptal crest (crista intrabullaris preseptalis) (PSC in Figs 3 and 5II). One more caudal-entotympanic lamina, that of the dorsal septum, apparently grows together with the preseptal crest as the posterior, septum-forming proper, inflation progresses (Figs 3 and 5II).

It should be stressed that the dorsal edge of the long arm of the caudal entotympanic, adjoining the rostral entotympanic (Hunt 1974: Fig. 25, S), 

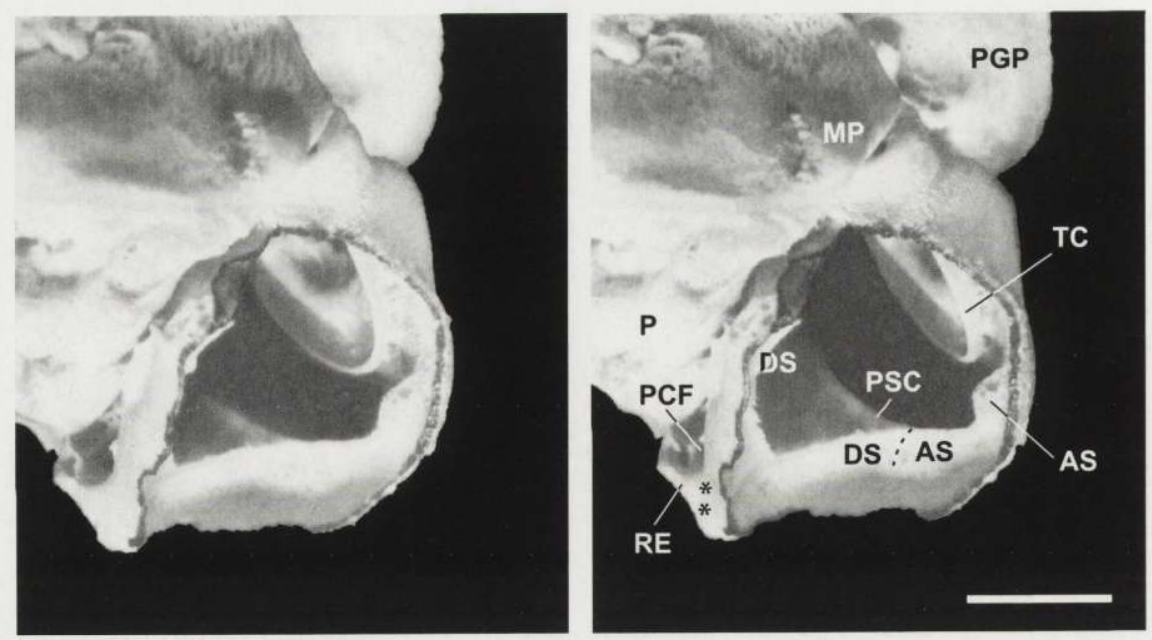

Fig. 3. Opened right auditory bulla of the juvenile Canis lupus, NMNH-P 3720, aged approximately 8 to 9 weeks (postero-ventro-lateral view). Exo- and basioccipitals are removed. Asterisks indicate the suture between the rostral and caudal entotympanics. Stereopair. Scale bar $5 \mathrm{~mm}$. See Appendix 2 for abbreviations.

distinctly visible in NMNH-P 1091, is later fused with the rostral entotympanic. The suture between them is already completely obliterated in the specimen NMNH-P 3720. The caudal-entotympanic edge in question may occasionally be seen in the form of a small cristid or fold even in subadults. In any case, however, it does not participate in the septum formation and the medial wall of the bulla above the partition is not formed entirely of the rostral entotympanic (Figs 5 and 6). The position of the latter, visible in ventral aspect of the exposed bulla, should be limited to a slight region contiguous to the junction of the petrosal and basisphenoid, and to a very narrow area of the promontorial surface lying somewhat posteromedially.

Thus, neither the ectotympanic nor caudal entotympanic 'bends' any of its edges into the cavity of the bulla to produce a septum. The latter is a result of the intense growth of the certain fragment of the caudal entotympanic, associated with relative stability of the bulla wall which surrounded this inflation previously, at the instant it appeared. This causes the surrounding wall to be overgrown by the caudal-entotympanic portion derived from the local inflation zone (Fig. 6).

For clarity, to designate the ventrolateral parts of the canid septum, which sit at the ectotympanic/caudal-entotympanic suture, the following two terms will be used: the 'anteroventral septum', septum intrabullare ventrale anterius (AS in Figs 4-6), and the 'posteroventral septum', septum intrabullare ventrale posterius (PS in Figs 4 and 5). The former corresponds to the 'ventral part of the canid septum' of Hunt's (1987: 64) in Canis latrans; the latter corresponds to the 'ventral septum' of Hesperocyon gregarius (Cope, 1873) in the terminology of Wang and Tedford (1994: 20). In addition, I use the term 'dorsal septum' (septum intrabullare 

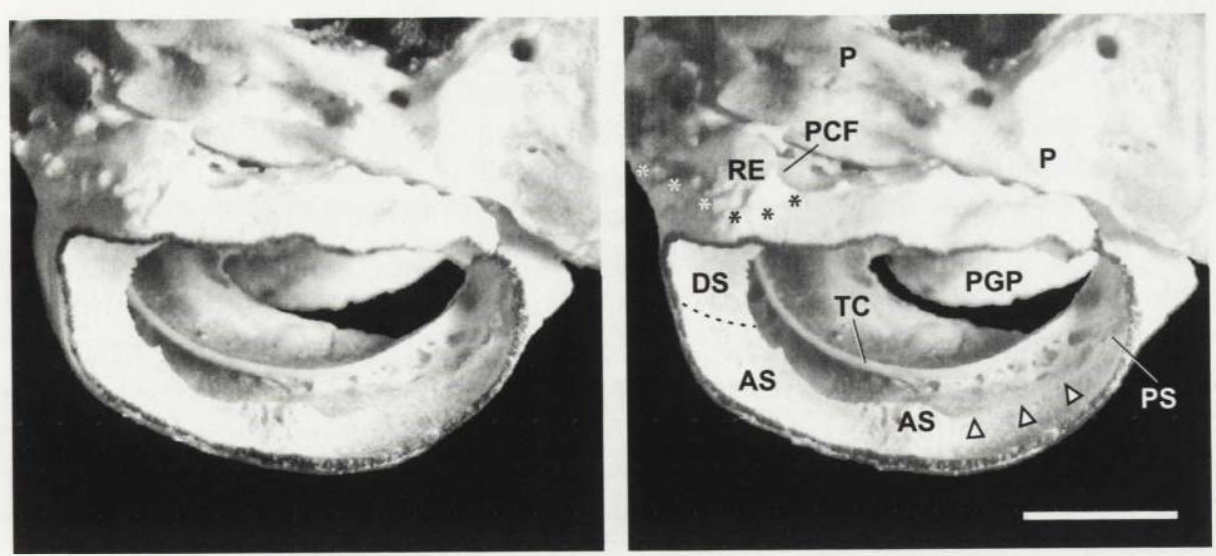

Fig. 4. Posteromedial view of the same bulla as in Fig. 3. Top is dorsal and right is posterolateral. The septumless part of the ectotympanic/caudal-entotympanic junction is indicated by triangles. Stereopair. Scale bar $5 \mathrm{~mm}$. See Appendix 2 for abbreviations.

dorsale) for the solely caudal-entotympanic dorsomedial segment of the canid partition (Figs 5 and 6), and the term 'ventral entotympanic sinus' (sinus entotympanicus ventralis) for the cavity which develops from the local inflation described above and creates a septum (Figs 5 and 6). The ventral entotympanic sinus is a part of the 'hypotympanic sinus' sensu Van Kampen (1905: 338-339) (compare Fig. 1 with Fig. 6C).

The caudal-entotympanic component of the septum is very thin. This is readily apparent in the region where the anterolateral and dorsal septa diverge from each other; the dorsal septum turns out to be much reduced in thickness in comparison with its previous condition as the bulla wall. The formation of the septum goes on concurrently with the transformation of bone to a compact condition as was pointed out by Van Kampen (1905). Importantly, this proceeds from the free edge of the partition to its base, implying rather the involvement of resorption phenomena than the bone growth (deposition). An additional detail is the presence of numerous erosive lacunae under the septum base, ie, in the area of the ventral entotympanic sinus invasion.

It is worth concentrating on the events responsible for the lack of a septum between the antero- and posteroventral septa. Lateral expansion of the caudal entotympanic, posterior to the anteroventral septum, occurs simultaneously with development of the tympanic crest and the ventral lip of the external auditory meatus. The specimen NMNH-P 3720 exhibits the following: (1) corresponding fragment of the ectotympanic, ie its part from the tympanic crest to the medial border of the bone, almost retains its initial width, (2) medial edge of this fragment 'turns' perpendicularly to the external meatal tube, (3) the ectotympanic and caudal entotympanic hold here their original edge-to-edge juncture in one plane merely oriented more vertically now (Fig. 4). 
Later stages of the auditory bulla development [exemplified in the specimens ZMKU 437 (4 months), ZMKU 438 (4 months), ZMKU 2861/26 (5 months) and the rest of the wolf material] show the further expansion of the ventral entotympanic sinus. This results in the following changes inside the bulla (Fig. 5III):

(1) Medial portion of the dorsal septum migrates upwards to be partly put to the petrosal, replacing with itself the initial dorsal edge of the caudal entotympanic. Occasionally, it does not reach such a condition, being fixed slightly ventrally.

(2) The anterior expansion of the ventral entotympanic sinus reaches the anteromedial corner of the bulla. Correspondingly, the base of the dorsal septum in this region of the bulla more or less approaches the rostral-entotympanic area. The latter trait is obviously responsible for the consideration of the septum as an in-bent dorsomedial edge of caudal entotympanic.

(3) The anteroventral septum widens, having an arcuate cross-sectional shape. The dorsal septum sometimes undergoes its own slight inflation. As a result, the partition plane may be flexed along the line of divergence of the dorsal and anteroventral septa. The line of flexion marks the anterior part of the initial suture between the ectotympanic and caudal entotympanic, which persists whithin the septum. This intraseptal fragment of the suture can be estimated from the

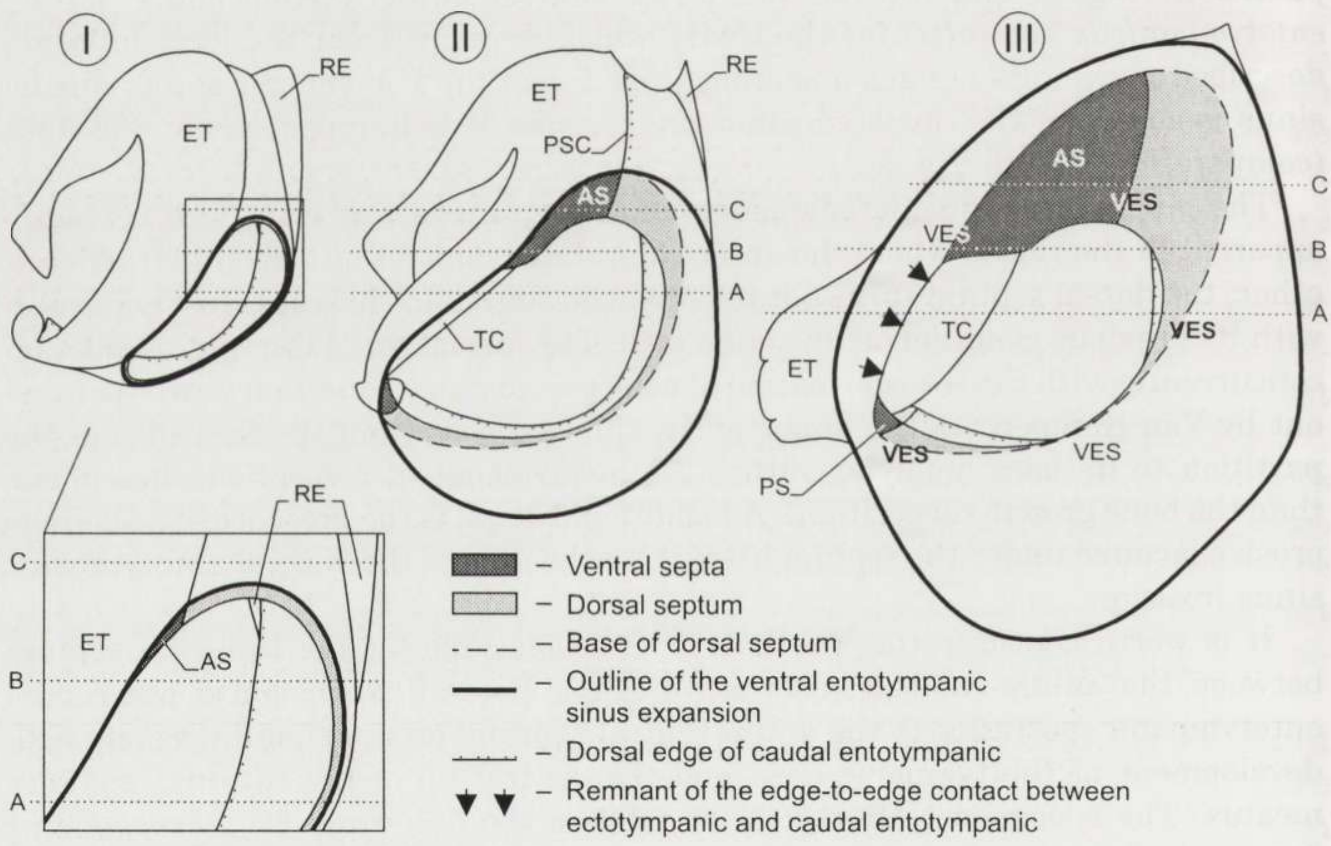

Fig. 5. Morphogenetic sequence of the auditory bulla in Canis lupus (ventral view of right bulla, top is anterior). Floor of each bulla is shown removed in the area occupied with the ventral entotympanic sinus (outlined by the bold line). I - cub about one to one and a half month old, II - approximately two-month-old cub, III - adult. Lines A, B and C indicate the transverse sections sketched in Fig. 6. See Appendix 2 for abbreviations. 
epsilon-shaped cross section of the septum. Such a condition creates an illusion that the growing edges of the ectotympanic and caudal entotympanic meet each other to be brought into the edge-to-edge contact (see Hunt 1987: Fig. 17).

(4) As the ventral entotympanic sinus advances, the preseptal crest (sitting at the ectotympanic/caudal-entotympanic suture anteriorly from the contact between these bones within the septum) usually disappears. Only the anterior end of the crest may sometimes persist. Hence the zone of the anterior inflation becomes partially or completely invaded by the ventral entotympanic sinus.

(5) The ectotympanic produces a clear-cut fold under the opening for the Eustachian tube and transversely to the axis of the latter. When the remnant of the dorsal edge of caudal entotympanic is discernible, it continues into this ectotympanic fold.

(6) The posteroventral septum frequently does not increase further and becomes subsequently imperceptible. When it persists, then, as a rule, it is close to the tympanic crest and sometimes almost coalesces with it. This is because the ectotympanic sector early ceases growing in width in this part of the bulla. The ventral septa always indicate the line of the ectotympanic/caudal-entotympanic junction.

(7) As the bulla growth progresses, the opening in the partition enlarges. This is caused by: firstly, partial resorption of the septum edge in the wake of deepening of the ventral entotympanic sinus and, secondly, slight 'rotation' of the tympanic ring to a more parasagittal plane.

\section{Morphogenesis of the intrabullar septum in Vulpes vulpes}

The youngest foxes examined were estimated to be about 8-10 weeks old. When compared with the wolf cub of the same age, they exhibit a very little extent of the ventral entotympanic sinus development. However, as in the case of the wolf, the medial margin of the sinus already makes a close approach to the caudal-entotympanic edge contacting the petrosal promontorium. The lack of younger specimens did not allow ascertaining a precise position of the medial margin of the incipient ventral entotympanic sinus. The available fox material, however, demonstrates that this margin, a future dorsal septum, also makes its appearance below the dorsal edge of caudal entotympanic.

In all the juveniles studied, the suture between the ectotympanic and caudal entotympanic is visible indicating that the growth of the ectotympanic in width is not stopped in the middle part of the suture early in development. Considerable relative width of the ectotympanic can be readily recognized not only from the texture of the bulla external surface, but also from the position of the intraseptal fragment of the ectotympanic/caudal-entotympanic initial suture. When detectable, this fragment indicates the medial edge of the ectotympanic.

The point of particular interest is the lateral margin of ventral entotympanic sinus, observed in the youngest fox-cubs (ISEA 3637/67/438, ISEA 3638/67/439) of one litter. Its anterior part in both specimens is in contact with the ectotympanic 
and shows the early stage of the anteroventral septum formation. In one of these cubs, the margin also coincides with the posterior length of the ectotympanic/caudalentotympanic suture, similar to that in the wolf. In another cub, however, it is not bounded posteriorly by the suture. Instead, it smoothly deviates laterally and in the form of a very weak but discernible ridge, runs on the ectotympanic approximately along the midline between the base of the tympanic crest and the medial edge of the ectotympanic, tapering caudally. The nature of this ridge is unknown. No its trace is found in the older fox-cubs; only the anteroventral septum formed through the application of the caudal entotympanic to the ectotympanic is retained.

\section{Definitive morphology of the canid septum}

Two basic types of the intrabullar partition can be distinguished among the recent canids examined. The first of them occurs in those species in which the ectotympanic constitutes only a slight portion of the bulla wall in comparison with the caudal-entotympanic contribution. Hence, the latter determines the ultimate size of the bulla; only the ventral lip of external auditory meatus and sometimes the anterior end of the tympanic ring are seen in ventral view of the intact bulla. As a consequence of the considerable development of the ventral entotympanic sinus, the septum is relatively high. The base of the anteroventral septum, viewed from the underside of the exposed bulla, always extends ventrolaterally to and beneath the tympanic crest (Fig. 5III). The ventral entotympanic sinus invades the anteromedial corner of the bulla. This morphotype is shared by the following species examined: Canis lupus, C. latrans, C. aureus, C. adustus, Cuon alpinus, Lycaon pictus, Chrysocyon brachyurus, Cerdocyon thous, Pseudalopex culpaeus, $P$. gymnocercus, $P$. sechurae, Nyctereutes procyonoides and Urocyon cinereoargenteus. The tendency in the gray wolf for the posteroventral septum to develop is also found in some individuals of $C$. aureus and $N$. procyonoides. In the African wild $\operatorname{dog}$ ZMMU S-84926, the posteroventral septum is even more pronounced than in the wolf specimens studied.

Chrysocyon brachyurus possesses an exceptionally well-developed septum partitioning the bulla cavity into two chambers connected by a small opening in the centre of septum. This structure was first described by Van Kampen (1905) and his observation is in good agreement with the model proposed here for interaction between the bulla elements in the course of development. The ridge on the upper surface of the maned wolf septum, revealed by Van Kampen (ibid.), is a medial edge of the ectotympanic and, correspondingly, of the ventral septum. In the specimen of C. brachyurus ZMMU S-160760, only the medial boundary of the opening in the partition is rounded; the lateral boundary is straight and oriented parallel to the longitudinal axis of the tympanic ring.

Thus, the difference of the maned wolf septum from those of the other canids except for the Paraenhydrocyon josephi septum described by Wang (1994) and Wang and Tedford (1994) - derives from the development of the middle part of the ventral septum which is not interrupted to form the antero- and posteroventral 
fragments. As traced above, in the gray wolf the edge-to-edge contact between the ectotympanic and caudal entotympanic does persist in this region (Figs 4 and 5III).

The second type (in Vulpes vulpes, Fennecus zerda and Alopex lagopus) is connected with a very large (relative to overall size of the bulla) tympanic ring making up the major portion of the bulla. Accordingly, the septum is extremely poorly developed, very low and oriented almost vertically. The base of the anteroventral septum does not extend laterally to the tympanic crest in ventral view of the exposed bulla. The base of the dorsal septum is far away from the junction between the caudal and rostral entotympanics, making it amply evident that the caudal-entotympanic edge contacting with the rostral entotympanic is not involved in the septum formation. The rostral entotympanic should otherwise build not only much of the bulla medial wall, but be also in extensive contact with the ectotympanic. If this were so, the relationship between the ectotympanic and rostral entotympanic would not correspond to the 'athictic' condition (for definition see Hunt 1987) inherent in canids. The anterior part of the ventral entotympanic sinus, confined by the partition, has the aspect of a shallow cleft not invading the anteromedial corner of the bulla. A posteroventral septum is absent.

$F$. zerda shows an enormously enlarged tympanic ring and a minimum size of the septum among the species studied. Judging from the bulla outer surface in the subadult ISEA M/4655/70, only a minute portion of the ectotympanic is brought into the surface-to-surface contact with the caudal entotympanic; correspondingly, the anteroventral septum is scarcely developed.

The partition of $V$. corsac seems to be a modification of the vulpine generalized type. As in V. vulpes, the tympanic ring in the corsac fox is widened, but its relative size is not so large as to prevent a considerable advancement of the ventral entotympanic sinus in the forward direction. The base of the resulting anteroventral septum in ventral view reaches the tympanic crest, though does not go beneath it. At the same time, the ventral entotympanic sinus extends into the anteromedial corner of the bulla to a degree that the anteriormost part of the sinus is found to be anterior to the forward tip of the ectotympanic. Such a combination of the wide tympanic ring and greatly increased ventral entotympanic sinus results in the unique shape of the latter: it is widened anteriorly from the septum edge.

In spite of differences in its size and topographic position, the septum in canids seems to be formed principally in the same way. The distinctive features of the Vulpes-Alopex-Fennecus septal pattern are explicable by larger relative size of the tympanic ring in these foxes.

\section{Discussion}

\section{Process of formation of the canid intrabullar septum}

The intrabullar septum in canids is formed through the development of the ventral entotympanic sinus, a cavity which enlarges additionally the hypotympanic space. This sinus appears as a separate inflation of the bulla wall, in the ventral 
part of the caudal-entotympanic posterior half. The initial boundary of the ventral entotympanic sinus remains relatively fixed, ie it almost fails to be resorbed. As a consequence, the sinus expands outside the bulla wall which previously surrounded this region. It is this expansion that gives rise to the septum, both the dorsal and ventral its sectors (Figs 5 and 6 ). Contrary to commonly accepted opinion, there is no septum-forming growth of the free edges of bones composing the canid auditory bulla.

Probably such a process was described by Van Kampen (1905) in the maned wolf. However, his hypothesis on the formation of the canid septum was obscure both in respect of the concrete sequence of morphogenetic stages, and in terms of the elements involved. Unfortunately, it was Van Kampen's mistaken belief on the non-autonomous ossification of the canid entotympanic (Fig. 1) that became very influential. As a result, the canid partition has long been considered to be formed entirely of the ectotympanic (eg Weber 1928, Van der Klaauw 1931, Grassé 1955, Gromova et al. 1962, Ewer 1973). At the same time, no one has ever tested his promising idea that the septum in canids is a part of the initial wall of the bulla, which enters subsequently into the bulla cavity.

(A)
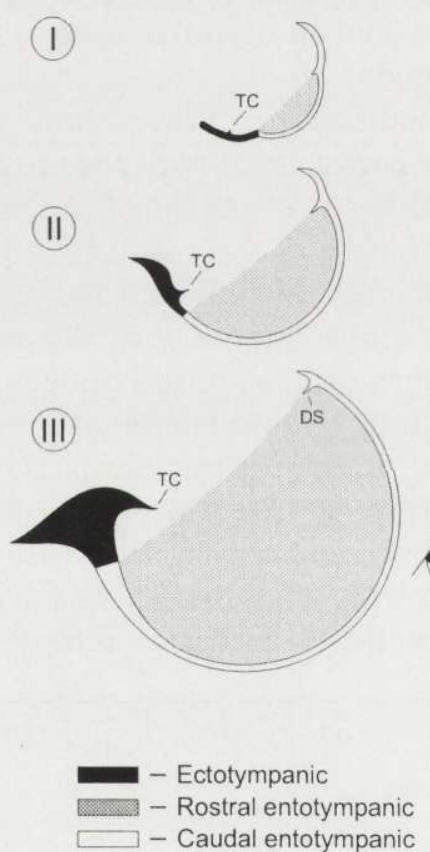

(B)

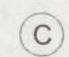

(C)

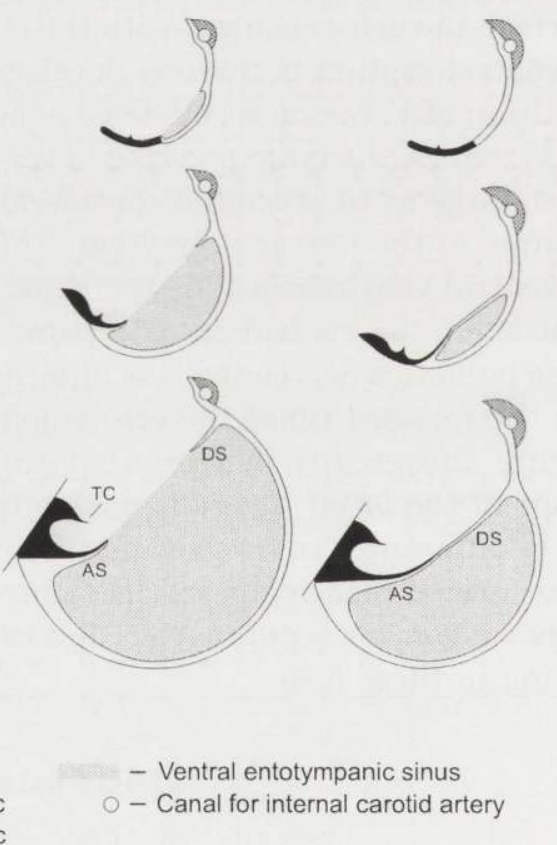

Fig. 6. Schematic demonstration of the septum morphogenesis as a result of the ventral entotympanic sinus development in a generalized canid auditory bulla. Cross-sectional views (top is dorsal and right is medial) at the ontogenetic stages I, II and III. See Fig. 5 for location of sections A, B and C. See Appendix 2 for abbreviations. 
In adult Canidae, the boundary of the opening for the ventral entotympanic sinus (in the septum) is represented by the following agents (Figs 5 and 6):

(1) Medially - by the edge of the dorsal septum, which almost or fully lies on the petrosal in middle and (in most species) posterior parts of the bulla. Thus the dorsal septum is able to replace with itself the initial dorsomedial edge of the caudal entotympanic in this region.

(2) Laterally - by the edge of the anteroventral septum anteriorly and by the edge-to-edge juncture between the ectotympanic and caudal entotympanic in middle and (in the majority of Canidae) posterior parts of the bulla. In some Hesperocyoninae and Caninae, the posteroventral septum occurs continuing medially into the posterior end of the dorsal septum. At last, the partition is developed at the spacing between the antero- and posteroventral septa in the hesperocyonine Paraenhydrocyon josephi (see Wang and Tedford 1994: Fig. 5a) and the canine Chrysocyon brachyurus.

\section{Bone composition of the canid intrabullar septum}

The dorsal septum is unquestionably of the caudal entotympanic. As concerns the ventral septa, they have to be rather bilaminar. The enclosure itself of the medial rim of ectotympanic into the bulla cavity is solely by way of the overgrowth of this rim by the caudal entotympanic of the ventral entotympanic sinus. This probable bilaminarity, however, is not demonstrable clearly at a macroscopic level because of such kind of fusion of two bone laminae that their periostea, even initially, do not remain included between them. Although this condition contrasts with that observed in felids in early stages of their postnatal ontogeny (Wińcza $1896,1898)$, the growth of the caudal entotympanic over the ectotympanic in canids occurs in the way closely similar to that in felids some time after the coalescence of the laminae of their partition. Therefore, both the canid ventral septum and the felid septum bullae can be equally considered bilaminar, at least until proved histologically that any of the laminae (in both the Cynoidea and Aeluroidea) is resorbed completely during the development.

\section{Independent origins of the cynoid and aeluroid septa}

The opinion that the canid intrabullar partition is not homologous with the aeluroid septum bullae has long been accepted but rested on the unwarranted assumptions that the canid septum is unilaminar and (1) formed of the ectotympanic alone (Van Kampen 1905) or (2) formed by the in-bent edge of caudal entotympanic (Hough 1953, Hunt 1974, Tedford 1976, Wang and Tedford 1994). None of these premises is corroborated by the present study. However, the data obtained confirm the conclusion that the intrabullar septa arose independently in the Cynoidea and Aeluroidea.

The fact that both the ventral and dorsal septa of canids are produced through the expansion of the ventral entotympanic sinus centres our attention on that caudal-entotympanic portion which initiates, by its forced inflation, the develop- 
ment of this sinus. Is it a homologue to the felid caudal entotympanic which takes part in the formation of septum bullae?

The felid septum is formed for the entire length of the ectotympanic/caudal-entotympanic suture including its anteriormost part near the opening for the Eustachian tube (eg Hunt 1987: Figs 11 and 12). In most canids, the edge-to-edge contact is retained here. The preseptal crest found in the two-month-old wolf (in the anterior part of the junction between the ectotympanic and caudal entotympanic) is brought into the composition of an anteroventral septum only as the ventral entotympanic sinus advances it. In consequence, in the adult wolf this part of the septum differs structurally from the corresponding fragment of the felid septum bullae. Although histological details of this event are not known either, in any case, in canids the ventral septum is formed through the expansion only of the ventral portion of the caudal-entotympanic posterior half. In felids, contrastingly, the entire caudal-entotympanic portion of the bulla inflates as a unit.

Therefore, the septum bullae and posterior (entotympanic) chamber of felids on the one hand, and the ventral septum and ventral entotympanic sinus of canids on the other, are formed of the different elements and are not homologues. In the former, the partition is a result of the inflation of the whole caudal entotympanic (navicular caudal entotympanic sensu Hunt 1987); in the latter, only a certain fragment, the ventral part of the caudal-entotympanic posterior half, is involved in the septum-forming inflation.

The question of why the canid bulla inflates in the fashion it does is yet to be answered. Novacek (1977) emphasized the need of careful histological studies on the ossification of mammalian entotympanic - this undoubtedly remains extended to the case of Carnivora. The close mapping of the entotympanic complex, if performed, would allow avoiding the risk consisting in the use of such oversimplified characteristics as 'septum complete or incomplete', 'bi- or unilaminar', 'caudal entotympanic inflated or not inflated', etc. The morphogenesis of the canid intrabullar septum shows that they may be only of limited, if any, utility in the reconstruction of carnivoran phylogeny until the origin and composition of the caudal-entotympanic part proper is allowed for. In addition, major lineages differ considerably in the palaeontologically documented time of the ossified entotympanic occurrence (see Hunt and Tedford 1993 for feliforms, Wang and Tedford 1994 for caniforms) and this is one more point to be cautious in treatment of the carnivoran caudal entotympanic as being the same element throughout the order.

\section{Occurrence of the ventral entotympanic sinus}

The ventral entotympanic sinus is found in all the canid species examined; a degree of its development is responsible for a definitive septal pattern. The observed morphological diversity of the intrabullar septum seems nonrandom and, when studied more thoroughly, might be used in systematics within at least the Caninae. Preliminary arrangement of the examined recent canids by their septal morphologies agrees (except for Urocyon cinereoargenteus, but see Geffen et al. 
1992) with their subdivision into two tribes on other morphological grounds (Huxley 1880, Tedford et al. 1995).

Of special importance is the question about the earliest occurrence of the ventral entotympanic sinus. The presently available information on the hesperocyonine intrabullar patterns seems to support the conclusion that this sinus first appeared at the basis of the canid clade, in the Late Eocene. Wang (1994) and Wang and Tedford (1994) suggested that the dorsal septum was acquired by members only of the advanced hesperocyonine taxa (eg Enhydrocyon Cope, 1879). At the same time, the medial wall of the bulla in $H$. gregarius bears the longitudinal ridge which runs in parallel with and noticeably below the dorsal edge of the caudal entotympanic (Wang and Tedford 1994: Fig. 1C, this paper: Fig. 7, DS). It is quite possible that this ridge represents exactly the dorsal septum, probably in its primitive condition. The similar arrangement, with the dorsal septum not yet reaching the promontorium and not approaching the rostral entotympanic, has been found in the earliest stages of the morphogenesis of ventral entotympanic sinus in the gray wolf. The base of the dorsal septum in the maned wolf is also situated below the bulla edge adjoining the petrosal.

Thus, in addition to the posteroventral septum occurring in $H$. gregarius, the inferred dorsal septum of this species can be expected to pass anteriorly into the anteroventral septum. Judging from the large relative width of the tympanic ring and from the weak inflation of the caudal entotympanic (Scott and Jepsen 1936: Pl. 13, Fig. 1a, Hough 1948: Fig. 9, Wang 1994: Fig. 9b), the anteroventral septum should be very low and rather restricted to the medial wall of the bulla. Indeed, such a pattern seems to be possessed by the Field Museum specimen UC495 in which there is a longitudinal ventral ridge starting 'at the anteromedian corner of the bulla', and there are tiny ridges developed 'in the depression immediately ventro-mesial to the carotid canal' (Clark and Guensburg 1972: 50).

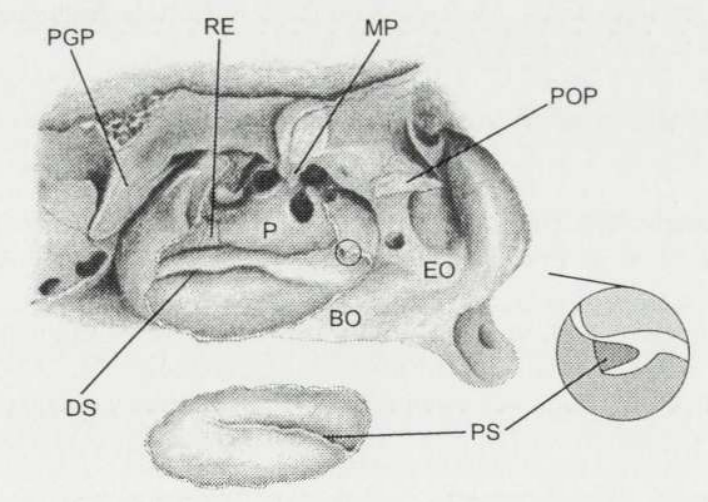

Fig. 7. Left basicranial region of Hesperocyon gregarius, F:AM 76163 (ventrolateral view). The dissected floor of the bulla is shown below. After Wang and Tedford (1994). Labels for presumed septa are added. See Appendix 2 for abbreviations. 
In any case, the arrangement of the septula in $H$. gregarius allows one to suggest that they point to the presence of ventral entotympanic sinus, being homologues to the canine intrabullar partitions. Should this be confirmed, the supposition of the independent appearance of dorsal septum in several hesperocyonine taxa (Wang and Tedford 1994) would become unnecessary and the family Canidae would be provided with an additional support for its monophyly in the scope proposed by Tedford (1978, Tedford et al. 1995, Wang and Tedford 1996). This unique morphological trait of the Canidae can be defined as 'the presence of the ventral entotympanic sinus'.

Acknowledgements: I am very grateful to A. V. Borissenko, S. V. Kruskop, A. Nadachowski, I. Y. Pavlinov, Z. V. Rozora, S. I. Zolotukhina for the access to the materials in their care and for permission to prepare some specimens. I am indebted to Y. A. Semenov, V. A. Topachevsky, X. Wang, M. Wolsan, I. V. Zagorodniuk and an anonymous reviewer for the reading and valuable comments on the manuscript. Finally, I wish to express my deepest gratitude to Yu. Semenov for the numerous discussions of the hyaenid auditory region, that have in large measure inspired me to this study.

\section{References}

Clark J. and Guensburg T. E. 1972. Arctoid genetic characters as related to the genus Parictis. Fieldiana: Geology 26: 1-76.

Ewer R. F. 1973. The carnivores. Cornell University Press, Ithaca: 1-494.

Flower W. H. 1869. On the value of the characters of the base of the cranium in the classification of the order Carnivora, and on the systematic position of Bassaris and other disputed forms. Proceedings of the Zoological Society of London: 4-37.

Flynn J. J. and Galiano H. 1982. Phylogeny of early Tertiary Carnivora, with a description of a new species of Protictis from the Middle Eocene of Northwestern Wyoming. American Museum Novitates 2725: 1-64.

Flynn J. J., Neff N. A. and Tedford R. H. 1988. Phylogeny of the Carnivora. [In: The phylogeny and classification of the tetrapods. Volume 2: Mammals. M. J. Benton, ed]. Systematics Association Special Volume 35B, Clarendon Press, Oxford: 73-116.

Geffen E., Mercure A., Girman D. J., Macdonald D. W. and Wayne R. K. 1992. Phylogenetic relationships of the fox-like canids: Mitichondrial DNA restriction fragment, site and cytochrome $b$ sequence analyses. Journal of Zoology, London 228: 27-39.

Grassé P.-P. 1955. Ordre des Fissipèdes (Fissipeda Blumenbach, 1791): Caractères anatomiques. [In: Traité de zoologie: Anatomie, systématique, biologie. Tome 17: Mammifères. Les ordres. Anatomie, éthologie, systématique. Fasc. 1. P.-P. Grassé, ed]. Masson, Paris: 194-212.

Gromova V. I., Dubrovo I. A. and Janovskaja N. M. 1962. [Order Carnivora. In: Fundamentals of palaeontology: Mammals. V. I. Gromova, ed]. Gosgeoltekhizdat, Moscow: 182-230. [In Russian]

Gursky I. G. 1973. Determination of Canis lupus L. age by skull. Vestnik Zoologii 3 (for 1973): 55-59. [In Russian with English summary]

Holz K. 1931. Vergleichende anatomische und topographische Studien über das Mittelohr der Säugetiere. Zeitschrift für Anatomie und Entwicklungsgeschichte 94: 757-791.

Hough J. R. 1948. The auditory region in some members of the Procyonidae, Canidae and Ursidae: Its significance in the phylogeny of the Carnivora. Bulletin of the American Museum of Natural History 92: 67-118.

Hough J. R. 1953. Auditory region in North American fossil Felidae: Its significance in phylogeny. United States Geological Survey Professional Papers 243-G: 95-115.

Hunt R. M. Jr 1974. The auditory bulla in Carnivora: An anatomical basis for reappraisal of carnivore evolution. Journal of Morphology 143: 21-76. 
Hunt R. M. Jr 1987. Evolution of the aeluroid Carnivora: Significance of auditory structure in the nimravid cat Dinictis. American Museum Novitates 2886: 1-74.

Hunt R. M. Jr and Tedford R. H. 1993. Phylogenetic relationships within the aeluroid Carnivora and implications of their temporal and geographic distribution. [In: Mammal phylogeny. Volume 2: Placentals. F. S. Szalay, M. J. Novacek and M. C. McKenna, eds]. Springer-Verlag, New York: 53-73.

Huxley T. H. 1880. On the cranial and dental characters of the Canidae. Proceedings of the Zoological Society of London: 238-288.

Linhart S. B. 1968. Dentition and pelage in the juvenile red fox (Vulpes vulpes). Journal of Mammalogy 49: $526-528$.

Markina A. B. 1962. [On the age craniology of foxes (Vulpes vulpes L.)]. [In: The problems of ecology, zoogeography and systematics of animals. A. I. Cherepanov, ed]. Trudy Biologicheskogo Instituta 8 , Izdatelstvo Sibirskogo Otdelenia AN SSSR, Novosibirsk: 171-179. [In Russian]

Mitchell E. and Tedford R. H. 1973. The Enaliarctinae, a new group of extinct aquatic Carnivora and a consideration of the origin of the Otariidae. Bulletin of the American Museum of Natural History 151: 201-284.

Munthe K. 1997. Canidae. [In: Evolution of Tertiary mammals of North America. Volume 1: Terrestrial carnivores, ungulates, and ungulatlike mammals. C. M. Janis, K. M. Scott and L. L. Jacobs, eds]. Cornell University Press, Ithaca: 124-143.

Novacek M. J. 1977. Aspects of the problem of variation, origin and evolution of the eutherian auditory bulla. Mammal Review 7: 131-150.

Scott W. B. and Jepsen G. L. 1936. The mammalian fauna of the White River Oligocene. Part 1: Insectivora and Carnivora. Transactions of the American Philosophical Society, New Series 28: $1-153$.

Tedford R. H. 1976. Relationship of pinnipeds to other carnivores (Mammalia). Systematic Zoology 25: 363-374.

Tedford R. H. 1978. History of dogs and cats: A view from the fossil record. [In: Nutrition and management of dogs and cats. M-23]. Ralston Purina, St. Louis: 1-10.

Tedford R. H., Taylor B. and Wang X. 1995. Phylogeny of the Caninae (Carnivora: Canidae): The living taxa. American Museum Novitates 3146: 1-37.

Turner H. N. 1848. Observations relating to some of the foramina at the base of the skull in Mammalia, and on the classification of the order Carnivora. Proceedings of the Zoological Society of London: 63-88.

Van der Klaauw C. J. 1931. On the auditory bulla in some fossil mammals, with a general introduction to this region of the skull. Bulletin of the American Museum of Natural History 62: 1-352.

Van Kampen P. N. 1905. Die Tympanalgegend des Säugetierschädels. Gegenbaurs Morphologisches Jahrbuch 34: 321-722.

Wang X. 1994. Phylogenetic systematics of the Hesperocyoninae (Carnivora: Canidae). Bulletin of the American Museum of Natural History 221: 1-207.

Wang X. and Tedford R. H. 1994. Basicranial anatomy and phylogeny of primitive canids and closely related miacids (Carnivora: Mammalia). American Museum Novitates 3092: 1-34.

Wang X. and Tedford R. H. 1996. Canidae. [In: Terrestrial Eocene-Oligocene transition in North America. D. R. Prothero and R. J. Emry, eds]. Cambridge University Press, Cambridge: 433-452.

Weber M. 1928. Die Säugetiere: Einführung in die Anatomie und Systematik der recenten und fossilen Mammalia. Zweite Auflage. Band 2: Systematischer Teil. Gustav Fischer, Jena: 1-898.

Wińcza H. 1896. Über einige Entwickelungsveränderungen in der Gegend des Schädelgrundes bei den Säugethieren. Bulletin International de l'Académie des Sciénces de Cracovie: 326-337.

Wincza H. 1898. [On some changes during the development of the base of the head in mammals]. Rozprawy Akademii Umiejętności, Wydział Matematyczno-Przyrodniczy, Serya 2, 13: 10-26. [In Polish]

Winge H. 1895. Jordfundne og nulevende Rovdyr (Carnivora) fra Lagoa Santa, Minas Geraes, Brasilien. Med Udsigt over Rovdyrenes indbyrdes Staegtskab. E Museo Lundii 2(2): 1-130. [n.v.] 
Wozencraft W. C. 1989. The phylogeny of the recent Carnivora. [In: Carnivore behavior, ecology, and evolution. J. L. Gittleman, ed]. Cornell University Press, Ithaca: 495-535.

Wyss A. R. and Flynn J. J. 1993. A phylogenetic analysis and definition of the Carnivora. [In: Mammal phylogeny. Volume 2: Placentals. F. S. Szalay, M. J. Novacek and M. C. McKenna, eds]. Springer-Verlag, New York: $32-52$.

Yudin V. G. 1986. [The fox of the Far East of the USSR]. DVNZ AN SSSR, Vladivostok: 1-284. [In Russian]

Yudin V. G. 1989. [The dental system of Canis lupus (Carnivora, Canidae) from the Far East of the USSR]. Zoologicheskiï Zhurnal 68: 115-123. [In Russian with English summary]

Received 23 October 1998, accepted 3 August 1999.

Appendix 1. List of specimens examined.

Alopex lagopus (Linnaeus, 1758): ISEA M/2069/60, NMNH-P 6377, NMNH-P 6378

Vulpes vulpes (Linnaeus, 1758): ISEA 3637/67/438 (juv.), ISEA 3638/67/439 (juv.), NMNH-P 288, NMNH-P 307, NMNH-P 474, NMNH-P 485, NMNH-P 489, NMNH-P 493, NMNH-P 565, NMNH-P 1394, NMNH-P 1397, NMNH-P 1398, NMNH-P 1399, NMNH-P 3146 (juv.), NMNH-P 3147, NMNH-P 3719 (juv.), NMNH-Z 478/292 (juv.), NMNH-Z 6084/37 (juv.), ZMKU 1563/18 (juv.), ZMKU 1582/37 (juv.), ZMKU 5768/199 (juv.)

Vulpes corsac (Linnaeus, 1768): NMNH-Z 382/1, NMNH-Z 383/2, NMNH-Z 384/3, ZMMU S-150196

Fennecus zerda (Zimmermann, 1780): ISEA M/4655/70 (subad.), ISEA M/4571/69

Urocyon cinereoargenteus (Schreber, 1775): ZMMU S-131515

Pseudalopex culpaeus (Molina, 1782): ZMMU S-38109

Pseudalopex gymnocercus (Fischer, 1814): ZMMU S-161363

Pseudalopex sechurae (Thomas, 1900): ZMMU S-150962

Cerdocyon thous (Linnaeus, 1766): ZMMU S-159357

Nyctereutes procyonoides (Gray, 1834): NMNH-P 8, NMNH-P 9, NMNH-P 11, NMNH-P 43, NMNH-P 49, NMNH-P 1180, NMNH-P 1396

Chrysocyon brachyurus (Illiger, 1815): ZMMU S-160760

Canis lupus Linnaeus, 1758: NMNH-P 1, NMNH-P 2, NMNH-P 1091 (juv.), NMNH-P 1182, NMNH-P 3140 (juv.), NMNH-P 3720 (juv.), NMNH-P 5857, NMNH-P 5860, NMNH-P 5865, NMNH-P 5869, ZMKU 437 (juv.), ZMKU 438 (juv.), ZMKU 2861/26 (juv.)

Canis latrans Say, 1823: ZMMU S-112958

Canis aureus Linnaeus, 1758: NMNH-P 1698, NMNH-P 5514, NMNH-Z 376/1, NMNH-Z 378/3, NMNH-Z 380/5, NMNH-Z 381/6, ZMKU 5306 (juv.)

Canis adustus Sundevall, 1846: ZMMU S-149608, ZMMU S-149609

Cuon alpinus (Pallas, 1811): ZMMU S-82308

Lycaon pictus (Temminck, 1820): ZMMU S-84926

Appendix 2. Abbreviations for anatomical terms.

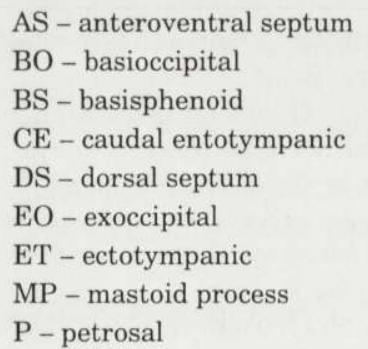

PCF - posterior carotid foramen

PGP - postglenoid process

POP - paroccipital process

PS - posteroventral septum

PSC - preseptal crest

$\mathrm{RE}$ - rostral entotympanic

TC - tympanic crest

VES - ventral entotympanic sinus 